\title{
STUDY OF DOMICILIARY CONSULTATIONS
}

\author{
BY
}

\author{
G. E. OWEN WILLIAMS
}

From the United Birmingham Hospitals

Recent trends in the administration of the Medical Services have tended to emphasize distinctions between medical practitioners of different vocations, and to draw attention to the need for re-synthesis of the profession as a whole. It is now well recognized that a close liaison between general practitioner and hospital is of great importance to the welfare of patients. The partnership of general practitioner and specialist in the field of domiciliary practice is equally important, and it was thought that a study of this relationship might be of value.

For this purpose the records of 1,014 domiciliary consultations have been examined. They were carried out by a general physician since the inception of the National Health Service, but not all of them under its auspices. The report includes the results of the consultations; the diagnosis, either provisional or final; and the immediate disposal of the patients. Unfortunately, some of the information was necessarily conjectural, and not all cases could be adequately followed up.

The age distribution of patients visited is shown in Table I; about half of them were over 60 years of age. The mean ages of males and females were 56.0 and 56.7 respectively, and for both sexes private patients were on the average several years older than patients seen through the National Health Service. In general practice it has been reported that female patients preponderate in both surgery and home consultations (Logan, 1953). In this series of domiciliary visits there was an excess of males (53.9 per cent. of the total).

\section{Results of Consultations}

In Table II the results of consultations are given in seven groups. Some consultations had more than one result, and the total number of results is therefore not the same as the number of consultations. The first group is one in which it was considered that the consultant had managed to make some material contribution, either to diagnosis or to treatment. This group accounted for approximately two-thirds of the practice. The method of classification, being based upon subjective assessment, is naturally liable to error, and it might be questioned whether a modification of the antibiotics used, a change in the dosage of digitalis, or the introduction

TABLE II

RESULTS OF CONSULTATIONS

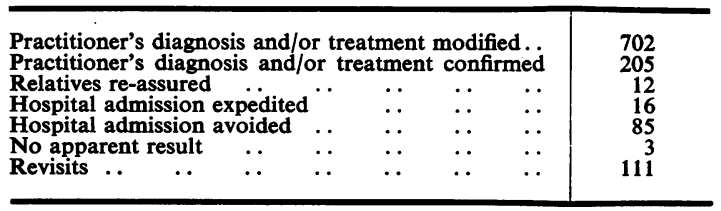

TABLE I

AGE DISTRIBUTION OF NATIONAL HEALTH SERVICE AND PRIVATE PATIENTS

\begin{tabular}{|c|c|c|c|c|c|c|c|c|c|c|c|c|c|c|c|c|}
\hline \multirow{3}{*}{ Sex } & \multirow{3}{*}{\multicolumn{5}{|c|}{ Type of Consultation }} & \multicolumn{8}{|c|}{ Age of Patients } & \multirow{2}{*}{\multicolumn{2}{|c|}{ Total }} & \multirow{3}{*}{$\begin{array}{c}\text { Mean } \\
\text { Age } \\
\text { (yrs) }\end{array}$} \\
\hline & & & & & & \multicolumn{2}{|c|}{$\overline{0-19}$} & \multicolumn{2}{|c|}{$20-39$} & \multicolumn{2}{|c|}{$40-59$} & \multicolumn{2}{|c|}{60 and over } & & & \\
\hline & & & & & & No. & $\%$ & No. & $\%$ & No. & $\%$ & No. & $\%$ & No. & $\%$ & \\
\hline \multirow{2}{*}{ Male } & National & 1 Health $\mathrm{S}$ & ice & $\ldots$ & $\ldots$ & 21 & $7 \cdot 9$ & 43 & $16 \cdot 2$ & 89 & $33 \cdot 6$ & 112 & $42 \cdot 3$ & 265 & 100 & $52 \cdot 4$ \\
\hline & Private & .. & .. & .. & . & 13 & $4 \cdot 6$ & 13 & $4 \cdot 6$ & 101 & $35 \cdot 8$ & 155 & $55 \cdot 0$ & 282 & 100 & $59 \cdot 3$ \\
\hline \multirow{2}{*}{ Female } & National & 1 Health $\mathrm{S}$ & rice & .. & $\vec{\ldots}$ & 13 & $4 \cdot 9$ & 44 & $16 \cdot 7$ & 77 & $29 \cdot 3$ & 129 & $49 \cdot 0$ & 263 & 100 & $55 \cdot 4$ \\
\hline & Private & $\ldots$ & .. & $\ldots$ & .. & 6 & $2 \cdot 9$ & 24 & $11 \cdot 8$ & 60 & $29 \cdot 4$ & 114 & $55 \cdot 9$ & 204 & 100 & $59 \cdot 6$ \\
\hline Total & $1 \quad \ldots$ & .. & .. & .. & . & 53 & $5 \cdot 2$ & 124 & $12 \cdot 2$ & 327 & $32 \cdot 2$ & 510 & $50 \cdot 3$ & 1,014 & 100 & 56.5 \\
\hline
\end{tabular}


of some other drug, could be regarded as a material contribution to treatment.

In the second group the general practitioner had apparently requested the consultation to reassure himself that his diagnosis was correct, and no further steps in treatment were necessary. This accounted for approximately one-fifth of the domiciliary practice. In this group have been placed cases in which the doctor required the support of a consultant in discussing his proposed course of action with relatives.

The third group is a small one in which the main reason for consultation was apparently to reassure relatives who were dissatisfied with the conduct of the case; only three consultations fell into this category.

In the fourth group, consultation was required to obtain admission of the patient to hospital. The consultant is sometimes called out for this purpose; a recent example was a request to see a patient urgently in need of admission to a general hospital, for whom a bed would be found by the Bed Bureau provided a consultant confirmed the necessity for admission. Although one does not deprecate this method of dealing with awkward cases, they should not, and do not, form a major part of the consultant's work.

The fifth group, also a small one, consists of cases in which the consultation apparently made it possible to avoid admission to hospital. In addition, one or two cases were found each year in which it was strongly suspected that the services of a consultant were not really required. Finally, about one-tenth (111) of the consultations were concerned with assessing the progress of patients who had already been visited on a previous occasion.

\section{Diagnosis}

The classification in Table III is based upon the clinical diagnosis recorded at the time of consultation, and is not usually supported by further evidence, though confirmatory information from hospital investigations, follow-up observation, and other sources, have been used when available. The two commonest disease groups were cardiac failure (158 cases) and respiratory disorders (151 cases), which together accounted for nearly one-third of the total number of consultations. Other conditions, such as carcinoma, neurological disorders, coronary thrombosis, cerebral thrombosis, and alimentary disturbances, all occurred with reasonable frequency, each accounting for approximately 7 per cent. of the total.

\section{DisPosal}

Of 1,014 cases shown in Table III, 321 (10.9 per cent.) required admission to hospital; 111 of these required admission urgently, and the remainder were put on the waiting list for admission for diagnosis or therapy. In addition, 93 patients, $9 \cdot 2$ per cent. of the total, required further investigation in hospital outpatient departments, or by private arrangements elsewhere.

TABLE III

DIAGNOSIS AND IMMEDIATE DISPOSAL OF PATIENTS VISITED

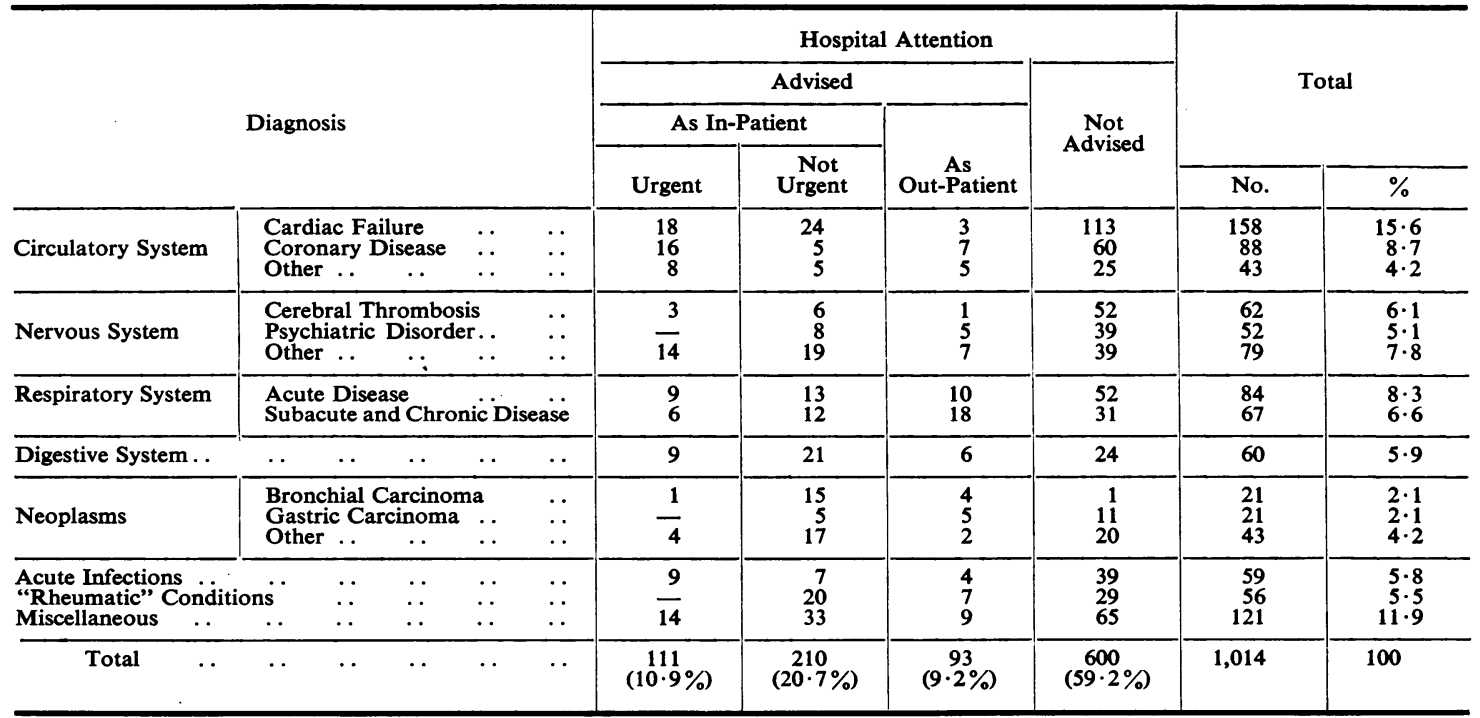


The hospital admission rate varied with diagnosis. For example, three-quarters of the cases of carcinoma of the bronchus were admitted to hospital, sometimes because of the frequent masking of signs by superadded acute inflammatory changes, and sometimes because bronchoscopic confirmation was necessary. In carcinoma of the stomach, on the other hand, admission was much less frequent, chiefly because clinical evidence of metastatic spread so often rendered hospitalization fruitless.

It is concluded that one of the prime requirements of the general practitioner is the establishment of a clinical diagnosis upon which a working plan of management can be based. Such diagnosis is possible in a surprisingly high proportion of domiciliary consultations, higher than is usually achieved in out-patient departments or in consultingroom practice. The patient who is sufficiently ill to be confined to bed generally presents physical signs or symptoms of sufficient severity or significance to enable an adequate assessment to be made in one-third of cases. This group includes both incurable and benign conditions. For the former; the domiciliary consultation is valuable in determining the course of action best suited to the circumstances, so as to spare the patient the mental and physical disturbance of removal to hospital or clinic for observation and subsequent return home untreated. Of the benign or treatable cases, the reassurance of patients or relatives, and the mutual support of consultant and practitioner, is sufficient to fulfill the purpose of the consultation.

\section{SUMMARY}

An analysis of 1,014 domiciliary consultations performed by a general physician at the request of general practitioners included an assessment of results of consultations; diagnosis; and immediate disposal of patients.

\section{REFERENCE}

Logan, W. P. D. (1953). “General Practitioners' Records". Studies on Medical and Population Subjects, No. 7. General Register Office, H.M.S.O., London. 